\title{
SOBRE A INVOCAÇÃO ÉPICA
}

Christina Ramalho

\section{RESUMO}

Este estudo propóe uma reflexão teórica sobre a invocação épica, recurso tradicionalmente presente nas epopeias. Utilizando-se de obras épicas de diversas épocas e origens, que não só ratificam o uso da invocação épica como demonstram a atualidade do gênero épico, discriminam-se aqui categorias a partir das quais esse recurso épico pode ser compreendido.

PALAVRAS-CHAVE: gênero épico; teoria épica do discurso; invocação épica.

\section{Introdução}

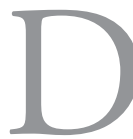

upla instância de enunciação - eu lírico/narrador -, presença dos planos histórico, maravilhoso e literário, heroísmo épico, deslocamento espacial ou simbólico, presença de dedicatória, proposição ${ }^{1}$, invocação, divisão em cantos e identificação de uma matéria-épica: todos esses aspectos norteiam o reconhecimento do caráter épico de um poema longo ${ }^{2}$. Sofrendo transformaçóes, tal como sempre ocorreu com outras manifestações dos gêneros literários, a epopeia atravessou os tempos viva e instigante, ainda que a crítica, ignorando essas transformações, tenha se equivocado ao considerá-la extinta a partir do momento em que deixou de obedecer aos padróes homéricos,

1 Sobre a proposição épica, ver RAMALHO, Christina. A cabeça calva de Deus: uma proposição e um oráculo. In: HÜHNE, Leda Miranda (Ed.). Poesia viva em revista 7. Rio de Janeiro: UAPÊ, 2012, p. 49-69.

2 Ver SILVA, Anazildo Vasconcelos da \& RAMALHO, Christina. História da epopeia brasileira. Teoria, crítica e percurso. vol. 1 Rio de Janeiro: Garamond, 2007. 
também erroneamente tomados como parâmetro inflexível para o reconhecimento do épico. Contudo, a observação atenta às diversas manifestaçôes épicas do discurso que, século a século, foram sendo produzidas, revela a atualidade do gênero e incita a se repensarem os enfoques teóricos dados ao gênero.

Neste estudo, ao enfocar a invocação épica, pretendo apresentar uma proposta de leitura teórica desse recurso, dimensionando as formas como se pode analisá-lo, e, ao mesmo tempo, ratificar a comentada atualidade do gênero, ilustrando as categorias elencadas com epopeias de diversas épocas e nacionalidades.

\section{A invocação épica}

$\mathrm{Na}$ epopeia, a invocação constitui, tradicionalmente, um recurso de efeito retórico relacionado a uma pretensa disparidade entre a dimensão do texto que vai ser escrito e o fôlego do poeta para realizá-lo. Assim, invocando a "musa", registra o poeta seu pedido de inspiração, amparo, energia e clareza, para que o resultado seja adequado à matéria-épica enfocada.

Considerando que as musas gregas sempre estiveram, simbólica ou alegoricamente, por trás dos talentos humanos, inspirando e, de certo modo, protegendo a criatividade dos artistas (em sua grande maioria, homens), era em geral a elas, no plural, ou a alguma delas, em especial, que o poema épico clássico se dirigia. Calíope, musa da eloquência, dona de bela voz e também considerada musa da epopeia, é, por isso, uma das presenças mais frequentes nas invocaçóes épicas. Mas, dadas as relações da epopeia com viagens feitas pelo mar, são igualmente constantes as alusões a ninfas como as nereidas ou as oceânidas. Ninfas locais, como as "tágides" portuguesas, também costumam aparecer.

A invocação, em geral, está posicionada na abertura das epopeias, justamente, como já foi dito, por estar associada à necessidade de preparo e fôlego para dar continuidade a uma criação que exige iluminação e perseverança. Contudo, nem sempre isso ocorre de forma destacada, embora, muitas vezes, a invocação mereça uma ou até mais estrofes só para si.

Com o advento do Cristianismo, a invocação a figuras da mitologia pagã ou foi rechaçada ou utilizada apenas para enfatizar o aspecto retórico e épico do "chamamento". Como destinatários da invocação, Deus e/ou as figuras relacionadas à religiosidade cristã se tornaram presenças constantes. Outro procedi- 
mento passou, no entanto, a ser comum: a dupla invocação - à musa e a Deus - cabendo à primeira cumprir uma função decorativa, relacionada à tradição épica; e, ao segundo, ser, de fato, o sustentáculo moral e religioso do canto.

A Idade Média e o Romantismo, cada qual a seu modo, influíram para que outro tipo de "musa" ganhasse destaque: a musa-mulher, a mulher amada, a detentora de reais poderes sobre o estado de espírito do poeta. Assim, mais um tipo de destinatário (no caso, destinatária) soma-se aos referentes pagãos e cristãos.

$\mathrm{Na}$ Modernidade, a invocação recebeu os mesmos adereços de criatividade que a epopeia como um todo. Além das imagens pagãs clássicas, das cristâs e da presença da musa-mulher, outras possibilidades de figuras invocadas surgiram. Entre elas, a figura coletiva do povo, a da pátria personificada, a do pressuposto leitor, a do herói ou a da heroína como interlocutores, entre outras.

$\mathrm{O}$ tom de uma invocação pode remontar à mera artificialidade de um recurso retórico propositalmente inserido para tornar a obra compatível com um pressuposto "modelo épico" como pode trazer o sentido da deprecação (súplica a alguém), do comando, da cominação (imprecação, ameaça), da apóstrofe (interpelação direcionada a alguém), da evocação (que apela para a memória ou para o sobrenatural), da convocação, da exaltação, da submissão, da fragilidade, etc. É necessário, na análise de uma invocação épica, reconhecer se o tom do chamamento tem significação dentro do dimensionamento da matéria-épica. Muitas vezes, principalmente nas epopeias mais modernas, é visível a importância do chamamento no sentido de provocar, por exemplo, a aderência do invocado à intenção do texto, criando uma espécie de "cumplicidade" épica.

Para melhor abordar a invocação épica, elaborei algumas categorias críticas a partir das quais se pode compreender a relevância desse recurso.

\section{Formas da invocação épica}

Este estudo da invocação épica leva em consideração três aspectos relacionados à sua presença na epopeia: o/a destinatário/a da invocação, o posicionamento da invocação no poema e o conteúdo da invocação.

Em termos de destinatário/a da invocação, é possível estabelecer as seguintes categorias: invocação pagã, invocação judaico-cristão, invocação humana, 
invocação à natureza, invocação à pátria, invocação simbólica, invocação multirreferencial, metainvocação e a autoinvocação. Explicito, a seguir, cada uma.

A invocação pagã ocorre quando a destinatária ou o destinatário do chamamento é uma figura da mitologia clássica ou de mitologias não judaico-cristấs. Na invocação judaico-cristâ, o(a) destinatário(a) da invocação pertence ao universo da espiritualidade bíblica ou, especificamente, da cristã. A invocação humana se dá quando o(a) destinatário(a) da invocação é um ser humano (um herói ou uma heroína, um poeta ou uma poetisa tomado/a como referência ou antecessor/a, uma personagem histórica, o ser amado, um povo ou uma coletividade social). $\mathrm{Na}$ invocação à natureza, a natureza ou alguns de seus elementos são chamados a socorrer o poeta em seu processo de criação. A invocação à pátria se faz presente quando a voz épica alude diretamente à pátria, dimensionando nacionalmente o seu canto. $\mathrm{Na}$ invocação simbólica, não se reconhece claramente a natureza do/da destinatário/a, embora se perceba que esse(a) destinatário(a) existe como referente. $\mathrm{Na}$ invocação multirreferencial verifica-se uma mescla de referentes pagãos, cristãos, místicos em geral e humanos. A metainvocação se reconhece quando a própria poesia ou o próprio poema são chamados pela voz épica a contribuir no processo de criação e elaboração textual. Na autoinvocação, a voz épica parece dialogar com sua própria capacidade de criação, em um processo de autoestímulo.

Já em relação ao posicionamento da invocação no texto, podemos ter: invocação tradicional, invocação mesclada à proposição (ou ainda à dedicatória), invocação reincidente e invocação multipresente. Cabe lembrar que há epopeias em que a invocação não aparece, constituindo casos de invocação ausente, o que de forma alguma impede o reconhecimento do caráter épico do poema, já que, como se afirmou na introdução, são muitos os aspectos levados em consideração para se compreender esse caráter. Discrimino a seguir essas categorias.

A invocação tradicional aparece inserida logo nos primeiros versos do poema, antes ou depois da proposição. A invocação mesclada à proposição (ou ainda à dedicatória) ocorre de tal modo que os versos em que aparece tanto pertencem a uma dimensão (invocação e proposição ou invocação e dedicatória) quanto à outra, sem que se possa separá-las. A invocação reincidente vai sendo repetida no decorrer do poema, como se a voz épica necessitasse, a cada momento, beber em sua fonte de inspiração. A invocação multipresente 
espalha-se pelo poema, assumindo, inclusive, destinatários/as diversos/as, daí a diferença entre ela e a reincidente.

Outra classificação parte da análise do conteúdo da invocação: invocação metatextual e invocação convocatória. A invocação metatextual, a mais comum, refere-se ao conteúdo centrado no fazer poético. O objetivo dessa invocação é, por meio do suposto apoio do/a invocado/a, poder apossar-se dos elementos necessários para a composição épica, sejam eles de natureza estética, referencial, mítica, etc. A invocação convocatória faz um chamamento aberto à participação dos (as) destinários(as) ou dos(as) ouvintes na matéria-épica, constituindo um efeito retórico que tanto busca aproximar o poema que se escreve do leitor coletivo ao qual se destina como, muitas vezes, chamar um ou mais destinatários a serem coautores simbólicos do que se escreve.

Sobre a invocação convocatória, também é importante salientar que o chamamento desloca-se do eixo da produção para o da recepção. A invocação convocatória revela o desejo da voz épica de constituir um corpo adjacente ao poema que se escreve, por meio do qual este se amplie, valorize e ganhe, mesmo, significado. Assim, esse tipo de invocação busca criar uma cumplicidade entre a instância de enunciação e a instância de recepção, refletindo num texto que se oferece à reescritura implícita no ato de ler.

De forma sintética, retomo todas as categorias propostas:

1. Quanto ao/à destinatário/a da invocação:

a) invocação pagá

b) invocação judaico-cristã

c) invocação humana

d) invocação à natureza

e) invocação à pátria

f) invocação simbólica

g) invocação multirreferencial

h) metainvocação

i) autoinvocação

2. Quanto ao posicionamento da invocação: invocação tradicional invocação mesclada à proposição (ou ainda à dedicatória) 

a) invocação reincidente
b) invocação multipresente
c) invocação ausente

3) Quanto ao conteúdo da invocação:

a) invocação metatextual

b) invocação convocatória

\section{Exemplos de invocação}

Recordando algumas epopeias e o modo como apresentam a invocação, fica mais fácil compreender as categorias anteriormente discriminadas. Vejamos a invocação em Ilíada:
Canta-me, ó deusa ${ }^{3}$, do Peleio Aquiles
A ira tenaz, que, lutuosa aos Gregos,
Verdes no Orco lançou mil fortes almas,
Corpos de heróis a cães e abutres pasto:
Lei foi de Jove, em rixa ao discordarem
O de homens chefe e o Mirmidon divino. ${ }^{4}$

Temos, nessa obra homérica, um caso de invocação pagã, mesclada à proposição e de conteúdo metatextual. Através da invocação já se sabe, portanto, de que matéria-épica se tratará: a ira de Aquiles. Sendo a "deusa" a destinatária do chamamento, o eu lírico/narrador pede a ela que "cante" a matéria-épica, fazendo-se, portanto, a porta-voz primeira do que se vai contar. É um recurso épico típico, sem apelo dramático ou emotivo.

Em Eneida, temos um exemplar caso de invocação pagá, tradicional e metatextual:

3 Para dar realce ao tema, em todas as citaçóes o/a destinatário/a da invocação aparecerá em negrito.

4 HOMERO, Ilíada. Trad. Manuel Odorico Mendes. E-books Brasil, 2009, p. 65. Disponível em: http://pensamentosnomadas.files.wordpress.com/2012/03/ilc3adada.pdf. Acesso em 12/02/2011. 
Musa, as causas me aponta, o ofenso nume,

Ou porque mágoa a soberana deia

Compeliu na piedade o herói famoso

A lances tais passar, volver tais casos.

Pois tantas iras em celestes peitos! ${ }^{5}$

Essa invocação centra-se na necessidade de informações sobre as conjunturas míticas que levaram o herói do poema a se ver enredado pelas tramas da deusa, no caso, Juno. A "Musa” é invocada, à moda épica tradicional, como a fonte necessária para as explicaçóes que justificarão as atribulaçóes a serem vividas pelo herói. Nesta abertura, não se pode, propriamente, reconhecer a matéria-épica em si, mas apenas a conjuntura que está envolvida nos eventos que serão contados.

Em Araucana (1569/1578/1589), a invocação ganha ares de súplica, indicando que a expectativa em relação à recepção daquele a quem a epopeia foi dedicada também influi para o estado de espírito da voz épica ao compor.

Suplicoos, gran Felipe, que mirada

esta labor, de vos sea recebida,

que, de todo favor necesitada,

queda condarse a vos favorecida:

es relación sin corromper sacada

de la verdad, cortada a su medida;

no depreciéis el don, aunque tan pobre,

para que autoridad mi verso cobre. ${ }^{6}$

Essa invocação humana, mesclada à dedicatória, tem, simultaneamente, conteúdo metatextual e convocatório, por centrar-se tanto na preocupação com as "verdades" do texto como no apoio que se espera que Dom Felipe II, rei a quem servia Ercilla, dê à obra.

5 VIRGíliO. Eneida. Trad. Manoel Odorico Mendes. E-Books, 2005, p. 15. Disponível em: http://www.ebooksbrasil.org/eLibris/eneida.html. Acesso em 12/02/2011.

6 ERCILlA, Alonso de. La Araucana. Santiago de Chile: Editorial Universitária, 1990, p. $17-18$. 
Em Orlando Furioso (1516) aparece uma invocação humana, mesclada à proposição e metatextual:

Diree de Orlando, simultaneamente, o que nunca foi dito em prosa ou rima, por amor ficou furioso e demente, tendo antes de sensato fama opima: se a que quase me fez o equivalente, e o pouco engenho sem cessar me lima, permitir que eu conserve o requerido para levar a bom fim o prometido. ${ }^{7}$

A substituição da musa mítica pela musa-mulher, como se viu antes, é um procedimento que costuma aparecer na poesia épica. Nesse caso, destaca-se o estado de espírito amoroso da voz épica e sua dependência em relação ao necessário apoio do ser amado. A autodesignação como poeta de "pouco engenho" também é presença comum nos textos épicos, dado o já conhecido e dimensionado fôlego que pede este tipo de criação. A valorização do que vai ser contado - "o que nunca foi dito em prosa ou rima" - parece justificar ainda mais a necessidade da invocação.

Exemplo de invocação judaico-cristã, tradicional e metatextual encontra-se em $A$ saga de Mem de Sá (1563), de José de Anchieta:

\section{LIVRO PRIMEIRO}

$[\ldots]$

Tu, ó luz clara do céu sereno, tu, meu

lume sem ocaso, imagem da glória pátria,

Jesus, instrui a mente cega; alumia de claro

raio o lume; tu, rica fonte, donde o gozo

flui aos cidadãos da pura urbe, pelo rio pleno,

fecunda meu peito, com opulento orvalho,

e funde ondas salutares de tuas fontes vivas;

rega a mente sedenta com o divo rio,

7 ARIOSTO, Ludovico. Orlando furioso. Cotia: Ateliê Editorial, 2007, p. 40. 
que eu possa lembrar os milagres da tua destra, que, há pouco, pelo amor da gente brasileira fez grandezas, quando do puro Olimpo os lumes orientais brilharam, pelos Tártaros dispersos. ${ }^{8}$

$\mathrm{Na}$ invocação cristã, como se viu, o apelo pode se dirigir, mais amplamente, a Deus, mas também pode se direcionar a ícones da religiosidade cristâ, como o maior deles, Jesus Cristo, ou Maria, alguns santos, santos de forma coletiva, anjos, etc. É o que ocorre em Martín Fierro, em que a invocação mesclada à proposição é cristâ, por a voz épica dirigir-se a "los santos del cielo", e metatextual, uma vez que a preocupação é que os santos "refresquen la memoria" e "aclaren" o "entendimiento" do eu lírico/narrador. Relembremos o trecho:
Pido a los santos del cielo
Que ayuden mi pensamiento:
les pido en este momento
que voy a cantar mi historia
me refresquen la memoria
y aclaren mi entendimiento. ${ }^{9}$

A invocação, no poema de Anchieta, pede a Jesus que instrua, alumie, fecunde, funde e regue a criação poemática e a mente do poeta. Esse horizonte amplo de expectativas em relação à fonte de inspiração, Jesus, valoriza o poder da figura invocada, atesta a filiação espiritual do autor, e, ao mesmo tempo, amplia o efeito retórico da invocação.

A bela invocação de As marinhas (1984), de Neide Archanjo, aparece deslocada no poema, pois se encontra posicionada no poema de abertura do Canto III, "Oceânico", constituído por diversas estrofes. Duas delas constituem a invocação mais explícita do poema, que, por sua vez, traz muitos versos cujo caráter remete à invocação épica. Vejamos as duas estrofes:

8 ANCHIETA, José de. A saga de Mem de Sá (De Gestis Mendi de Saa). Tradução Fabricio Possebon. João Pessoa: Ed. Universitária UFPB/Zarinha Centro de Cultura, 2007, p. 27.

9 HERNÁNDEZ, José. Martin Fierro. Buenos Aires: Editorial Losada, 1999, p. 25-26. 
A nostalgia com que vos contemplo

terra minha é imensa,

debruçada que estou

aqui onde a terra se acaba

e o mar começa

neste cabo avançado

cheio de uivos e tantos ventos

roca de gemidos

e ainda assim silêncios

lúmen breu trevas

em que invoco

a Senhora destes Continentes

pois me faço ao largo

onde Deus está perenemente só.

\section{Senhora Conceição}

Senhora dos Navegantes

ouvi meu apelo enclausurado

em torno destas dunas

e fazei cantar o coro de Oxum

vossas sereias

mágico lamento a me espinhar

sob a oferenda que espalhei

saudando as estrelas-guias

as ondinas e os indaiás

os calungas e os tarimás

enfunada procissão que abre agora

esta estrada de mar.

Oh, bela Uiara,

vem coberta de esperança

que preciso contornar o labirinto

e entrar no vosso reino

rosácea azul brilhante

onde há centenas de milhões de anos

fez-se a vida 
onde sentada em seu mistério

a eterna mãe me espera

marinha água cintilante. ${ }^{10}$

Compondo uma típica invocação multirreferencial, essas estrofes de $A s$ marinhas tomam como destinatárias entidades místicas de três origens: cristã, afro-brasileira e indígena, o que dá à epopeia de Archanjo uma particular inspiração, já que toca no cerne da religiosidade nacional. De outro lado, como um todo, a invocação no poema é multipresente, porque há muitos outros trechos em que se percebe a intenção própria do "invocar". Eis um exemplo: "Como vos cantar cavaleiros das águas/ habitantes perenes do delírio/ marítimas criaturas?” (Canto III, 1984:50). Além disso, quanto ao conteúdo, observa-se, nas estrofes citadas, um conteúdo metatextual, no que se refere à consciência do poema, e convocatório, no que alude à desejada presença das criaturas míticas do mar na trajetória épica que se escreve. A expressão "apelo enclausurado" dá veemência à convocação.

Helena Parente Cunha, em Caminhos de quando e além. Diálogos com os poemas de Fernando Pessoa (2007) - poema longo que, segundo visão por mim expressa no posfácio da obra, integra perfeitamente o percurso épico pós-moderno brasileiro - apresenta nos poemas intitulados "Estação 1", "Estação 2" e "Estação 3" questóes relacionadas à criação poemática, que remetem à invocação simbólica, uma vez que a voz épica se dirige à emblemática imagem de um "rei", cuja identidade ganha diversas significaçôes.

Estação 1 (trecho)

O que escrever neste breve instante que impóe do que não disponho?

No oco rumor desta página, em palidez de pergaminho ou cera

ou lisa claridade da tela e das teclas,

como dizer do dito que se disse,

no já vivido que não se viveu?

${ }_{10}$ ARCHANJO, Neide. As marinhas. Rio de Janeiro: Salamandra, 1984, p. 60-61. 
As urzes estão à espreita do milagre.

Eu? Sim, também aguardo milagres e aberturas de fronteiras

neste não haver tempo para pensardes nem esperardes o quê.

$[\ldots]$

O que faço e por que faço?

Se não sei, apenas escrevo e sigo as ordens do rei que me enviou. $^{11}$

Estação 2(trecho)

Aguardo as ordens do rei para me mover

e mover a mensagem a ser levada

aos quatro e quarenta e quatro cantos do globo,

aos sete vezes sete setembros do tempo.

Que mensagem? Perguntais. Eu nem pergunto.

Apenas aguardo as determinações superiores de que sabe por que vim.

$[\ldots]$

Se não sei ler, senhor, como seguir teus estes tais comandos?

Esfinges me inscrevem nos olhares parados em pedra.

Abre-me as portas de adentrar a pirâmide, dá-me a senha para as decifrações, dá-me a chave secreta dos subterrâneos. Saberei o que queres e cumprirei teus decretos. ${ }^{12}$

Estação 3 (trecho)

11 CUNHA, Helena Parente. Caminhos de quando e além. Diálogos com poemas de Fernando Pessoa. Rio de Janeiro: Tempo Brasileiro, 2007, p. 33-34.

12 Ibidem, p. 35-36. 
Começar é preciso.

No começo está oculto o roteiro da chegada e o perigo do abismo. $^{13}$

Diversos são os aspectos que nos permitem identificar, nos três poemas que abrem Caminhos de quando e além, uma invocação simbólica, multipresente e metatextual. O destinário dos questionamentos recebe uma aura mítica, sendo chamado de "rei", e, mais adiante (no decorrer do poema), de "mestre", o que cria uma virtual parceria na criação, em que a figura do rei situa uma hierarquia nesse processo de "criar" a palavra.

Os breves extratos do poema demonstram a consciência poética acerca da necessidade de se estabelecer um roteiro para a criação, além de uma perfeita compreensão do que, simbolicamente, também referencia a matéria-épica. Neste sentido, o termo "mensagem" (aludindo à obra épica de Fernando Pessoa, por associação óbvia, dado o subtítulo do poema) assume valor de matéria-épica. Saber que seu canto terá que se espalhar pelos "quatro e quarenta e quatro cantos do globo", em termos de espaço, e "aos sete vezes sete setembros do tempo", em termos de tempo, ratifica a ideia do épico, e permite o reconhecimento da sensação do "canto nobre e extenso" que é missão do poeta épico, que, por isso, necessita de ajuda para realizá-lo.

Na obra Cidade do mais antigo nome (2009), do cabo-verdiano José Luiz Tavares Duarte Belo, encontramos um caso de invocação simbólica, mesclada à proposição e metatextual:

I

Embora fraco no engenho,

Sigo a voz que me ordena:

Escreve, para que não se pense

Que aqui só a pedra ficou de herança

- Aqui um povo novo avança

com um ímpeto que descalcifica

a pertinaz sentença dos deuses. ${ }^{14}$

13 Ibidem, p. 37.

14 BELO, José Luiz Tavares Duarte. Cidade do mais antigo nome. Lisboa: Assírio \& Alvim, 2009, p. 6. 
Tal como o "rei", que ordena em Caminhos de quando e além, aqui a referência simbólica é uma "voz". A usual referência ao "engenho" remete o tom do poema ao épico. De outro lado, quando o eu lírico/narrador se revela submetido a uma voz que "ordena" ou comanda o ato de escrever, o poema fica, metalinguisticamente, projetado no âmbito de uma realização de valor coletivo, o que se acentua na posterior alusão ao "povo novo" que "avança".

Outro exemplo interessante vem de Gerardo Mello Mourão, em Invenção do mar. Carmen Saeculare $(1997)^{15}$. O "Canto I" se inicia com o poema I e os versos: "Ai flores do verde pinho/ ai pinhos da verde rama/ coroado das flores do verde pinho/ eu não quero este mar - eu quero o outro:” (1997, p. 24). Tal procedimento se repetirá no decorrer do mesmo poema, o que fará das "flores do verde pinho" as destinatárias da invocação. Retomando, pois, uma imagem das cantigas de amigo de Dom Dinis, a voz épica constrói, por meio da invocação à natureza, um referente por meio do qual demarcará o outro elemento da natureza que é a matéria-épica do poema: o mar. Ainda que inventiva, a invocação neste caso é tradicional e seu conteúdo metatextual, já que centrado no fazer poético.

Jorge de Lima, em Invenção de Orfeu (1952) ${ }^{16}$, trabalha a invocação de forma multirreferencial e multipresente, com ênfase no conteúdo metatextual. Há vários trechos da obra que remontam à invocação, o que gera uma imagem de constante recriação da palavra e, por consequência, do próprio poema. A autoinvocação e a metainvocação também são reconhecíveis, principalmente em função desse centramento metatextual.

Outro exemplo vem de Pablo Neruda, que, em Canto General (1950), invoca, através do eu lírico/narrador, a terra natal e ancestral, e a ela confessa que a "palabra aún no nacida de mi boca" estaria previamente contaminada pelo sentimento da terra:

Tierra mía sin nombre, sin América, estambre equinoccial, lanza de púrpura, tu aroma me trepó por las raíces

15 MOURÃO, Gerardo Mello. Invenção do mar: Carmen sæculare. Rio de Janeiro: Record, 1997. 16 LIMA, Jorge de. Invenção de Orfeu. Rio de Janeiro: Aguilar, 1974. 
hasta la copa que bebia, hasta la más delgada palavra aún no nacida de mi boca. ${ }^{17}$

No caso da invocação de Canto General temos um claro exemplo de invocação a terra/pátria, tradicional e metatextual.

Há epopeias em que a invocação vem carregada de referentes épicos, marcando a intenção do autor de filiar-se a essa tradição literária, ainda que o procedimento, em epopeias mais atuais, de certo modo diminua o grau de inventividade que caracteriza as epopeias modernas e pós-modernas. Foi assim, provavelmente baseado nos modelos canônicos de epopeia, que Manuel de Azevedo concebeu a invocação de $A$ tragédia do Nyenburg. Episódios dos Tempos Coloniais do RN (2006):

\section{Cantus Introitus}

\section{I}

\section{Ó Magno Vate Homero!}

Vertai bênçãos a ideia

De redigir em sextilhas,

A Batávica Epopeia,

Tal qual fizeram as Musas,

Com sua obra "Odisseia”!

II

Também rogo a ti, Camões!

Pra que a inspiração Lusíada

Possa conduzir-me ao pódio

Da poética olimpíada,

Com essa obra singela,

Com esta pequena "Ilíada".

III

Sagrado Bardo Latino,

Pai da "Divina Comédia",

$\overline{17}$ NERUDA, Pablo. Canto general. Prólogo y cronología de Fernando Alegria. Caracas: Ayacucho, 1976, p. 20. 


\section{Salve Dante Alighieri! \\ Clareai esta tragédia, \\ Com vossa acha poética, \\ Que acendeu a idade média!}

IV
A ti, prezado leitor,
Eu peço vossa atenção
Para a leitura dos versos,
Feitos com dedicação,
E muita fidelidade
À original narração. ${ }^{18}$

Em que pesem o fato de o texto citado não mostrar um compromisso do autor com a renovação do gênero e a presença da revelação explícita do desejo de se colocar à altura de Homero, Camóes e Dante, implícito nas relaçóes que o poema estabelece entre as obras dos três autores e a que se vai escrever, tem-se, nesse texto de abertura de $A$ tragédia do Nyenburg, um exemplo de invocação multirreferencial, tradicional e metatextual. $\mathrm{O}$ apelo à atenção do leitor assume, contudo, tom convocatório, inserindo na obra a expectativa da recepção. O poema de Manuel de Azevedo, portanto, utiliza, desde a invocação, referências e formatos épicos tradicionais para fazer reconhecer sua intencionalidade épica, sem que isso, contudo, signifique uma sintonia real com as formas do épico, se consideradas válidas as formulaçóes acerca das transformações pelas quais o gênero passou.

Como último exemplo, refiro-me à obra $A$ cabeça calva de Deus (2001), do cabo-verdiano Corsino Fortes. Composta por três livros Pão \& Fonema (1974), Árvore \& Tambor (1986) e Pedras de Sol \& Substância (2001), reunidos, em 2001, sob o título de $A$ cabeça calva de Deus ${ }^{19}$, a produção épica de Fortes oferece um repertório vasto para consideraçóes sobre o gênero épico.

18 AZEVEDO, Manuel de. A tragédia do Nyenburg. Episódios dos tempos coloniais do RN. Natal: Lei Djalma Maranhão Cordéis Publicados, 2006, p. 25-26.

19 FORTES, Corsino. Pão \& Fonema. Poema. Lisboa: Editorial Amadora, 1974; FORTES, Corsino. Árvore \& tambor. Lisboa: Instituto Caboverdiano do Livro: Publicações Dom Quixote, 1986; FORTES, Corsino. A cabeça calva de Deus. Lisboa: Publicaçóes Dom Quixote, 2001. 
Em $A$ cabeça calva de Deus (2001) é invocação multirreferencial, pois há, no conjunto da obra, um somatório de referentes aos quais a voz poética se dirige, ainda que varie o tom das invocaçôes. A predominância, dentro desse contexto multirreferencial, será, todavia, a invocação humana.

Há também, contudo, uma representativa presença da metainvocação, que merece análise. $\mathrm{O}$ eu lírico/narrador, diversas vezes, dirige-se ao poema, como que o instigando a ganhar vida própria, a se integrar à matéria-épica: a formação identitária de Cabo Verde. Vejamos um trecho de Pão \& Fonema:

\section{II}

\section{Poeta! todo o poema:}

geometria de sangue $\&$ fonema

Escuto Escuta

Um pilão fala

árvores de fruto

ao meio do dia

E tambores

erguem

na colina

Um coração de terra batida

E lon longe

do marulho à viola fria

Reconheço o bemol

Da mão doméstica

Que solfeja ${ }^{20}$

Tanto o caráter multirreferencial do destinatário quanto a metainvocação se justificam quando se apreende o direcionamento da obra para uma constituição coletiva ou para um canto cuja voz espelhe o "ser cabo-verdiano" de forma ampla. Assim, o chamamento deve ser pluralmente espargido de

${ }_{20}$ FORTES, Corsino. A cabeça calva de Deus. Lisboa: Publicações Dom Quixote, 2001, p. 17. 
modo a alcançar os "outros" de que também se compóe essa identidade. Entre esses "outros", o poema. Segue mais um trecho, agora de Pedras de Sol \& Substância, em que a pedra, elemento da natureza carregado de simbologia dentro do contexto cultural e identitário cabo-verdiano, é a destinatária da invocação:

Pedra! só serás poema $\&$ prosa

Antes \& depois

Se no povoado! a multidão te propuser

À tradição que nos devora

Entre o pão da parábola $\mathrm{E}$ a praça do parlamento ${ }^{21}$ (2001, p. 271).

No que se refere ao posicionamento da invocação em $A$ cabeça calva de Deus, compreende-se que, dado seu caráter multirreferencial, seja natural a multipresença. Seguindo o ritmo das abordagens aos planos histórico e maravilhoso, a invocação se distribuirá pela obra, corroborando com a intenção do coletivo.

Quanto ao conteúdo, há os dois registros: a invocação metatextual e a convocatória. Cabe, no entanto, à segunda um papel decisivo: justamente o de dar coesão à identidade que se referencia.

\section{Conclusão}

Inúmeros seriam os exemplos que permitiriam ilustrar as reflexões sobre o recurso da invocação épica. Contudo, importa, nesta conclusão, destacar que tal abordagem, se utilizada como orientação para a análise de um poema épico, não pode prescindir de aprofundamentos e questionamentos tais como: quais são os efeitos que a invocação estudada promove na leitura da epopeia em foco?; por que determinados/as destinatários/as foram mais significativos para certo/a autor/a a ponto de estarem presentes em sua obra em detrimento de outros/as?; em que pontos determinadas formas de invocação dialogam com a concepção literária (e épica) da época em que se insere o poema enfocado?; por que em alguns poemas épicos o tom convocatório se faz necessário?;

21 Ibidem, p. 271. 
etc. $\mathrm{O}$ que aqui apresentei, enfim, foi um caminho para, a partir das considerações sobre a invocação épica, dar destaque a uma manifestação literária atual, aberta e carente de maior atenção por parte da crítica.

\section{ACERCA DE LA INVOCACION ÉPICA}

\section{RESUMEN:}

Este estudio propone una reflexión teórica acerca de la invocación épica tradicionalmente presente en los poemas épicos. Por medio de citaciones de obras épicas de todos los tiempos, que no sólo corroboran el uso de la invocación épica como prueban la actualidad del género épico, son propuestas aquí categorías a partir de las cuales este recurso épico puede ser comprendido.

PALABRAS CLAVE: género épico; teoria épica del discurso; invocación épica.

Recebido em: 26/03/2013

Aprovado em: 26/08/2013 